\title{
Rural-urban gradient and sustainability in Spain: a municipal-scale approach
}

\author{
O. de Cos, P. Reques \& M. Marañón \\ Research group: "Espacios y Territorio: Análisis y ordenación”, \\ Departamento de Geografia, Urbanismo y Ordenación del Territorio, \\ University of Cantabria, Spain
}

\begin{abstract}
This article attempts to provide a methodological approach to the insufficiency of the statistical criteria used to determine that a municipal area is rural (less than 2,000 inhabitants), semi-urban (2,000 to 10,000 inhabitants) or urban (more than 10,000 inhabitants). In contrast to this system, a conceptual and methodological alternative is proposed, based on different territorial, demographic and economic indicators, which enables the traditional rural-urban duality or dichotomy to be overcome in order to empirically confirm the hypothesis of continuum or rural-urban gradient within the Spanish territory. With this aim, we analyse and map different indicators, related positively or negatively to the degree of urbanization, referred to as municipal areas in Spain.

The territorial indicators were: number of nuclei per square kilometre to measure the population dispersal, the distance to urban nuclei, the occupation intensity of the territory, the percentage of population working outside the primary sector, the index of masculinity in adults related to the feminine over-emigration in rural environments, the degree of ageing, the demographic growth rates in different periods of recent history and the percentage of the working population with secondary and university study. All these indicators were standardized to enable them to be dealt with together and to make them comparable with the aim of creating a representative synthetic indicator. The end result has enabled the elaboration of a synthesis map in which the differing degrees of urbanization within the Spanish territory, and the importance that the urban system has in explaining it, are demonstrated. The article also alludes to the problems of sustainability that exist nowadays in the extreme poles of the
\end{abstract}


proposed model: namely, maximum rural level, derived from the high degree of depopulation and ageing, and the maximum degree of urbanization, derived from the high degree of concentration and of demographic growth.

Keywords: rural-urban gradient, standardization, cartographic model, degree of urbanization.

\section{Justification: aims and objectives}

The principal aim of this study is to provide a significant methodological solution for the determination of the rural-urban gradient in Spain, which overcomes the rigidity of the criterion based on demographic size. This is the most used statistical criterion; so, rural character is often associated with entities of fewer than 2,000 inhabitants, semi-urban character is attributed to places between 2,000 and 10,000 inhabitants and, finally, urban is identified with units of more than 10,000 inhabitants, as is done by the Spanish National Institute for Statistics. In the same way, as the OCDE (1994) proposed, the demographic size in relative terms is also used as a defining criterion for specifying the rural or urban character of a European municipal area, based on a population density threshold lower or higher than 150 inhabs $/ \mathrm{km}^{2}$.

In contrast to these methodological proposals (which are functional for the production of statistics but excessively simplifying for consideration of territorial patterns of population establishment and sustainability), a theoretical-conceptual alternative is proposed, based on different territorial, demographic and economical indicators. It enables the traditional rural-urban duality or dichotomy to be overcome and also the hypothesis of continuum or Spanish territorial ruralurban gradient to be empirically demonstrated, using the municipal area (and also, to a lesser extent, the population nucleus) as an analysis unit.

The work aims to empirically demonstrate the existence of the rural-urban gradient in Spain, as a basis for later consideration of the sustainability problems suffered by the extremities of the model proposed.

The problems of sustainability in the most rural spaces appear to be linked to their high degree of ageing and depopulation, which occur in numerous areas of the country, fundamentally in mountainous zones. These problems originate from the fact that human beings, below some critical thresholds (which some authors calculate to be 9 inhab $/ \mathrm{km}^{2}$ ), no longer act as a factor for ecological equilibrium; within Spain there are paradigmatic examples.

On the contrary, the spaces with the highest levels of urbanization, suffer problems of sustainability linked to their high level of demographic concentration and growth as well as to the daily transit of their inhabitants. Moreover, due to their progressive character, the current problems of sustainability show a trend, which far from levelling off, will tend to increase in the coming decades. 


\section{The theoretical basis: rural-urban duality or rural-urban gradient?}

Nearly five decades after the publication of the work of Lewis Munford "The City in History" [1], there is still no substantial agreement about defining what is "urban" and what is "rural". The challenges have increased in recent decades as a consequence of the changes undergone in one type of space and the other: new phenomena and new concepts are emerging, such as "urban crisis" (Ferrer [2]) or the "rural renaissance" (Kayser [3]). "Rural" and "Urban" are not now elements of a polarized and dual model, but elements of a system in which the idea of continuum or rural-urban gradient reflects the current reality (Marois [4]).

On the other hand, theories such as "demographic urbanization" (Davis [5]), "urbanization of rural areas" (Baigorri [6]; Newby [7]), or "rururbanization" (Bauer and Roux [8]), oblige the redefinition in the developed countries of the concept of "countryside" or rural area (Frouws [9]) or, simply, to do without it as an absolute category (Hoggart [10]; Hoggart et al. [11]; Schmitt and GoffetteNagot [12]).

In developed countries, different methods have been proposed to empirically develop the hypothesis of continuum or rural-urban gradient. In France ambitious studies have enabled the elaboration of a rich and complex typology of rural spaces that contemplates the following groups: periurban municipalities, agricultural municipalities, residential tourism municipalities, extremely rural municipal areas. In this way, the rurality enables diverse approaches and, without doubt, economic-functional ones are the most important (Blanc [13]).

Rural spaces have an increasingly clear multi-functional character, but the extra-urban spaces are even more so: in addition to their basic agricultural function, they are also residential, recreational, environmental, landscape, economic (logistic centres, shopping malls, etc.), as well as scientific and educational, due to the presence of agricultural colleges, and research centres.

In England and Wales, P. Cloke, one of the first authors to propose the term "counterurbanisation" [14], has been developing since the 80 s different research works analyzing the degree of rurality of the English and Welsh counties and their recent evolution (Cloke and Edwards [15]; Cloke and Little [16]; Cloke and Thrift [17]). In these works, the authors considered different parameters (about twenty of them) linked to socio-demographic census information (employment, growth of the population, degree of ageing, etc.) and to housing or land use.

Clout [18] considered as rural those municipal areas that have a relatively low population density, a poor provision of infrastructures, a low proportion of secondary and tertiary sector assets, and a predominance of primary sector related land use (agricultural, forestry, etc.), in a model that was proposed for Europe.

Other authors propose qualitative approaches and highlight the perceptions and meanings, stating that "rural" and "urban" are to a great extent "social constructions" although they appear to be segmented, not just for specific spaces, 
but in relation to aspects of social reality (Halfacree [19]; Paniagua and Hoggart [20]; Paniagua [21]).

This succinct summary of the diversity of work that has been proposed on the concepts and methods adapted for analyzing the degree of urbanization of the territory demonstrates the interest that this field of study has had for the international scientific community. In fact, it is still an open research field that must respond to the emerging challenges of sustainability, differentiated in the dual "urban-rural" territorial patterns, in which environmental conflict is obvious: contaminated urban spaces and environmentally unsustainable ones are contrasted with environmentally sustainable rural spaces, but undergoing the pressure of the urban-metropolitan spaces, which see them simply as reserve spaces.

\section{Methodology: cartographic modelling based on standardized variables}

The achievement of the principal aim of this study is based on exploration, analysis and cartographic representation of different indicators, positive or negatively related to the degree of urbanization, in the context of the 8,112 municipal areas in Spain.

\subsection{Selection of representative variables}

The indicators incorporated into the final synthetic index used to determine the degree of urbanization of the territory are structured in five principal axes: geographic or territorial, structure-related demographic, evolutional or growthrelated demographic, economic and socio-educational. All these enable a cartographic model to be built up in which operators and variables synthesize initial standardized values in a continuous final index.

The thematic structure described is taken as a reference for the methodological explanation; to do so, the different variables defining the ruralurban gradient will now be detailed in thematic axes from the territorial, demographic, economic and socio-educational viewpoints:

- The geographic factor has grouped four variables, which are without doubt determinant when measuring the degree of urbanization or rurality of the Spanish municipal areas: the distance from the centre of the municipal area to a city of more than 30,000 inhabitants and more than 100,000 inhabitants, the number of population nuclei per square kilometre in each municipal area, which is a fundamental indicator to measure the degree of population dispersion within the territory and the gross population density (inhabitants per square kilometre) which permits an approximation to the degree of occupation of the territory and the demographic pressure on the geographical space.

- From the structural demography viewpoint two indicators are incorporated: the masculinity index in adults (15-65 year-olds) due to its 
relation with feminine over-emigration in rural zones and the degree of ageing, demonstrated as it is in the geographical analysis of the rural population both in greater ageing and in the feminine over-emigration in rural zones.

- The evolutional profile of the rural and urban zones is integrated from the rates of demographic growth in three key moments from the point of view of processes of extra-urbanization and metropolization (19811991, 1991-2001 and 2001-2007).

- The economic axis was measured from a single but unequivocal indicator: the percentage of non-agricultural active population.

- The socio-educational character de la population was approached from the percentage of the working population with secondary or higher qualifications.

\subsection{Standardization of variables}

All these indicators have been standardized to transfer them to a common scale that enables them to be worked with together and to be compared, which is a necessary condition to create a representative synthetic indicator. The formula used for direct type variables is:

$\mathrm{Z}_{\mathrm{i}}=$ value of $\mathrm{x}$ in the municipality $\mathrm{i}-$ average of $\mathrm{x}$ for the total of municipality/ $\sigma_{\mathrm{x}}$

The application of this formula enables diagnostic maps to be generated with the lowest extreme values linked to the concept of "ruralisation" and a final synthesis map can be elaborated in which the differing degrees of urbanization of the Spanish territory are shown and the importance that the urban system has in explaining these differences is demonstrated.

\subsection{Weighting and estimation of the synthetic indicator}

The cartographic model designed incorporates, after the previously described standardization, a weighting phase in which a differential weighting is established, expressed in decimals, that is applied to each of the previously described thematic axes, sharing this weighting fairly among the indicators that are integrated into the factor under consideration.

Thus, the weighting given to each factor is: 0.5 to the geographical factor; 0.1 to the structural demographic factor; 0.2 to the evolutional demographic factor linked to the population dynamics over recent decades and, finally, 0.1 points to both the economic factor and to the socio-educational one.

$$
\mathrm{Z}_{\mathrm{w}}=\left(\mathrm{F}_{\mathrm{g}} * 0.5\right)+\left(\mathrm{F}_{\mathrm{de}} * 0.2\right)+\left(\mathrm{F}_{\mathrm{dd}} * 0.2\right)+\left(\mathrm{F}_{\mathrm{e}} * 0.1\right)+\left(\mathrm{F}_{\mathrm{se}} * 0.1\right)
$$


where:

- $\mathrm{Z}_{\mathrm{w}}=$ Weighted average of the standardized values

- $\mathrm{F}_{\mathrm{g}}=$ Geographic factor $* 0.5$

- $\mathrm{F}_{\mathrm{de}}=$ Demographic factor (structure) $* 0.1$

- $\mathrm{F}_{\mathrm{dc}}=$ Demographic factor (growth) $* 0.2$

- $\mathrm{F}_{\mathrm{e}}=$ Economic factor $* 0.1$

- $\mathrm{F}_{\mathrm{se}}=$ Socio-educational factor $* 0.1$

\section{Discussion of results and conclusions}

The index obtained has an interpretation which could be termed degree of urbanization with positive and negative values which are directly proportional to the level of urbanization reached by each municipal area over the base of the previously described indicators.

The cartographic representation of the final synthetic index (Figure 1) demonstrates the existence of dual rural-urban behaviour which is continuous in the territory starting from a series of intermediate degrees of urbanization in turn demonstrates the existence of a rural-urban gradient, from the principal urban and metropolitan systems (in bright red, with values over 1) to the zones with the most rural features at the opposite extremity (with levels below -1).

In these spatial patterns, the accessibility and ease of travel factors have had a fundamental role. Therefore, the configuration of dynamic residential expansion

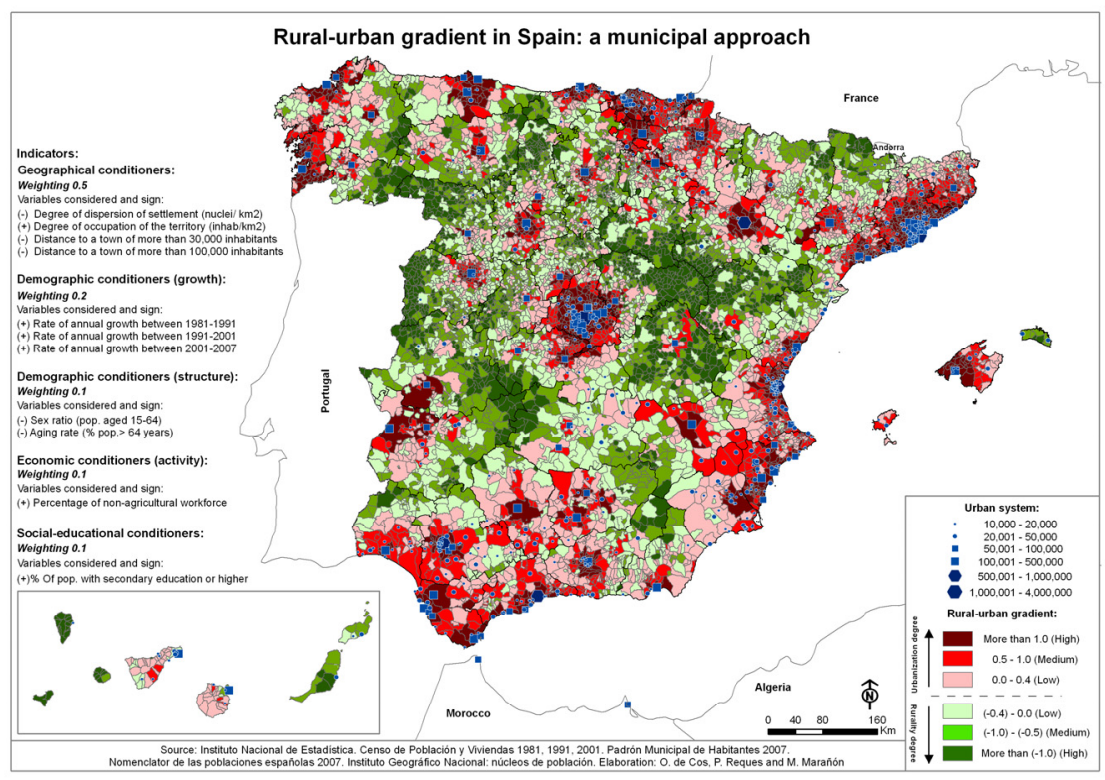

Figure 1: Cartographic synthesis of rural-urban gradient in Spain (colour online only). 
into previously rural municipal areas generates a series of intermediate levels that fulfil the principles of diffuse logic in which the territory does not behave in a categorical way at all, but where the realities of urban and rural environments overlap and mix according to a model in which the dynamic part puts pressure on the regressive one and where the polarization of the realities gives rise to a rural-urban gradient that is not exempt from sustainability problems, especially at the extremities of the model proposed.

Sustainability issues in the most rural spaces are linked to their high degree of ageing and depopulation, which are provoked in many areas of the country, fundamentally mountainous ones, by problems derived from the fact that humans, below a critical threshold, which some authors calculate to be 9 inhabitants per square kilometre, no longer act as a factor for ecological equilibrium.

In contrast the spaces with the maximum level of urbanization have sustainability problems linked to their high degree of demographic concentration and growth and the daily mobility requirements.

\section{References}

[1] Mumford, L., (1979): The City in History. New York.

[2] Ferrer, M. (1988): "La naturaleza de la crisis urbana". En: Espacios rurales y urbanos en áreas industrializadas. Pp. 101-115.

[3] Kayser, B. (1990): La renaissance rurale. Ed. Armand Colín. París.

[4] Marois, C. (1996): "Le couple ville-campagne: une cohabitation changeante" L 'action nationale, 2: 201-207.

[5] Davis, K. (1979): "Urbanización de la población humana", Scientific American ( ${ }^{\circ}$ monografico sobre la ciudad"

[6] Baigorri, A. (1983), "La urbanización del mundo campesino", Documentación Social, 51, pp. 143-148.

[7] Newby, H. (1980): 'Urbanización y estructura de clases rurales', Agricultura y Sociedad, 14, pp. 9-48. NEWBY, H. (1986): "Locality and Rurality: The Restructuring of Rural Social Relations". Regional Studies, volume 20-3, pp. 209-215. -NEWBY, H. (1980): 'Urbanización y estructura de clases rurales', Agricultura y Sociedad, 14, pp. 9-48.

[8] Bauer, G. \& Roux, J. M. (1976): La rurbanísation ou la ville éparpillée, Seuil, París.

[9] Frouws, J. (1998): "The Contested Redefinition of the Countryside. An Analysis of Rural Discourses in The Netherlands". Sociología Ruralis, volume 38-1, pp. 54-68.

[10] Hoggart, K. (1988): "Not a Definition of Rural". Área, 20.1, pp. 3540.Hoggart, K. (1990): "Let's Do Away with Rural". Journal of Rural Studies, volume 6, pp. 245-257.

[11] Hoggart, K.; Buller, H. and Black, R. (1995): Rural Europe. Identity and Change. Arnold, London. 
[12] Schmitt, B. and Goffette-Nagot, F. (2000): "Definir l'espace rural? De la difficulté d'une définition conceptuelle á la nécessité d'une délimitation statistique". Economie Rurale, 257, pp. 42-55.

[13] Blanc, M. (1997): "La ruralité: diversité des approches". Economie Rurale, 242, pp. 5-12.

[14] Cloke, P. (1985): “Counterurbanisation: A Rural Perspective”. Geography, 70, pp. 13-23.

[15] Cloke, P. and Edwards, G. (1986): "Rurality in England and Wales 1981: A Replication of the 1971 Index". Regional Studies, 20, pp. 289-306.

[16] Cloke, P. and Little, J. (1990): The Rural State? Limits to Planning in Rural Society. Clarendon Press, Oxford.

[17] Cloke, P. and Thrift, N. (1994): "Refiguring the "Rural". En Cloke et al. Writing the rural. Five Cultural Geographies. P. Chapman, pp. 1-6, Liverpool.

[18] Clout, H. (1993): “What Is the Rural?”. In: Clout, H. European Experience of Rural Development. The Rural Development Commission, Mimeo, London.

[19] Halfacree, K. H. (1995): "Talking about Rurality: Social Representations of the Rural as Expressed by Residents of Six English Parishes". Journal of Rural Studies, volume 11, issue 1, pp. 1-20.

[20] Paniagua, A., Hoggart, K. (2002): "Lo rural, ¿hechos, discursos o representaciones? Una perspectiva geográfica de un debate clásico". Información Comercial Española - Monográfico Globalización y Mundo rural, no 803 , nov-dic, pp. 61-71.

[21] Paniagua, A. (2001): "Agri-environmental Policy in Spain. The Agenda of Socio-political Developments at the National, Regional and Local Levels". Journal of Rural Studies, volume 17-1, pp. 81-98. 